\title{
Study the Neurological Improvement after Surgical Management of Traumatic Paraplegia in Traumatic Thoracolumbar Fractures
}

\author{
Subarna Misra ${ }^{1}$, Subhankar Mukherjee ${ }^{2 *}$, Upal Banerjee ${ }^{1}$, Abhishek Chattopadhyay ${ }^{1}$, Anindya Sasmal ${ }^{3}$, Shashi Dinkar $^{4}$
}

\begin{abstract}
Background: Traumatic paraplegia is an unanticipated catastrophe in an individual's life, posing a huge economic as well as social burden. We evaluated all the patients for neurological improvement after surgical management of traumatic paraplegia in traumatic thoracolumbar fractures. Materials and Methods: The prospective study was conducted in the department of orthopedics of a tertiary care teaching institute in Kolkata, West Bengal, India. The patients were evaluated by X-ray of spine (anteroposterior and lateral view) and sometimes computed tomography scan. In most cases, pedicle screw with plate or rod was used and posterior stabilization and posterior fusion with corticocancellous bone graft from posterior iliac crest were done. Pre-operative and post-operative neurological charts (according to Frankel's grade and American Spinal Cord Injury Association score [motor and sensory]) were maintained with regular assessment for proper post- operative neurological recovery assessment. Results: Forty-six patients in whom posterior stabilization of the spine was done in this institution and followed up for a period ranging from 6 months to 2 years, 4 of 46 patients lost follow-up. Remaining 42 patients were considered for the study. When decompression done within the $1^{\text {st }}$ week in incomplete paraplegia, $80 \%$ of the patients show Grade 3 power return, whereas $25 \%$ of the patients show return of Grade 3 power when decompression done in the $3^{\text {rd }}$ week in incomplete paraplegia cases. In complete paraplegia cases, $11 \%$ of the patients had return of power up to Grade 3 when decompression done within the 1 week, where no cases showed return of Grade 3 power when decompression done after the $2^{\text {nd }}$ or $3^{\text {rd }}$ week. In incomplete paraplegia, $80 \%$ of the patients had onset of sensory recovery within 1 week, when the decompression done within the $1^{\text {st }}$ week. In complete paraplegia, $11 \%$ of the patients had sensory recovery within 2 weeks when decompression done within 1 week. Conclusion: Hence, our conclusion is that early decompression definitely has some role regarding motor and sensory function return, both in complete and incomplete paraplegia.
\end{abstract}

Keywords: Complete, Incomplete, Neurological improvement, Paraplegia, Thoracolumbar fractures, Trauma

Asian Pac. J. Health Sci., (2020); DOI: 10.21276/apjhs.2020.7.3.15

\section{INTRODUCTION}

Biomechanically, thoracolumbar junction is susceptible to injury and is the most commonly injured portion of the spine. ${ }^{[1,2]}$ Once one spine injury is diagnosed, it is especially important to examine the rest of the spine since non-contiguous injuries can be present $15 \%$ of the time. ${ }^{[3,4]}$ Three main categories with a common injury pattern were formed: Type A - vertebral body compression (compression force), type B - anterior and posterior element injury with distraction (tensile force), and type $\mathrm{C}$ - anterior and posterior element injury with rotation (axial torque). ${ }^{[4]}$

The treatment options for the unstable thoracolumbar spine fractures and fracture dislocations are ridden with controversies. Most authors agree that neurological improvement is independent of the treatment modality. ${ }^{[5,6]}$ However, the advocates of surgical decompression point at theoretical advantages of surgery in improving neurological deficits. Lately, consensus is evolving around the world for stabilization of spine with fusion and instrumentation in unstable fractures. Surgical treatment can be by anterior, posterior, lateral, or anteroposterior (AP) approaches. As most orthopedicians and spine surgeons are more experienced in posterior approach, it is a safe alternative. Many instruments are available to stabilize spine by posterior approach. ${ }^{[7]}$

Traumatic paraplegia is an unanticipated catastrophe in an individual's life, posing a huge economic as well as social burden. The health care does not end with fixation of spine and inculcates a programmed rehabilitation and preventive management plan involving multiple personnel and family members. Early surgery
'Department of Orthopedics, ICARE Institute of Medical Sciences and Research, Haldia, West Bengal, India

${ }^{2}$ Department of Orthopaedics, KPC Medical College and Hospital, Kolkata, West Bengal, India

${ }^{3}$ Department of Radiodiagnosis, ICARE Institute of Medical Sciences and Research, Haldia, West Bengal, India

${ }^{4}$ Department of Anesthesiology, ICARE Institute of Medical Sciences and Research, Haldia, West Bengal, India

Corresponding Author: Dr. Subhankar Mukherjee, Assistant Professor, Department of Orthopaedics, KPC Medical College and Hospital, 1F, Raja Subodh Chandra Mullick Road, Jadavpur, Kolkata, West Bengal - 700 032, India. E-mail: doctor.subhankar@gmail.com

How to cite this article: Misra $S$, Mukherjee $S$, Banerjee $U$, Chattopadhyay A, Sasmal A, Dinkar S. Study the Neurological Improvement after Surgical Management of Traumatic Paraplegia in Traumatic Thoracolumbar Fractures. Asian Pac. J. Health Sci., 2020; 7(3):70-76

Source of support: Nil

Conflict of interest: None

Received: 02/12/2019 Revised: 24/01/2020 Accepted: 10/02/2020

and comprehensive rehabilitation markedly reduces the overall morbidity of spinal cord injured patients by enabling the patient to lead an independent life. ${ }^{[8]}$

In a developing country like India, where tertiary health care is not universally accessible and acceptable, the consequences of 
traumatic paraplegia and loss of manpower are well imaginable. Data of traumatic paraplegia at a tertiary care hospital, Kolkata, were analyzed with the analysis of the results of surgical management of traumatic paraplegia, complete or incomplete. We evaluated all the patients for neurological improvement after surgical management of traumatic paraplegia in traumatic thoracolumbar fractures.

\section{Materials and Methods}

The prospective study was conducted in the department of orthopedics of a tertiary care teaching institute in Kolkata, West Bengal, India. The Institutional Ethics Committee permission was sought before enrollment of study subjects in the above study. The study participants were followed up for 6 months in post-operative period. The cases included in this study were the patients attending outdoor and emergency with traumatic paraplegia involving the dorsolumbar spine.

\section{Inclusion Criteria}

The presence of traumatic paraplegia (complete or incomplete) and fulfilled the following criteria:

- Fracture and/or dislocation of the vertebra of dorsolumbar spine involving D8-L5 spine

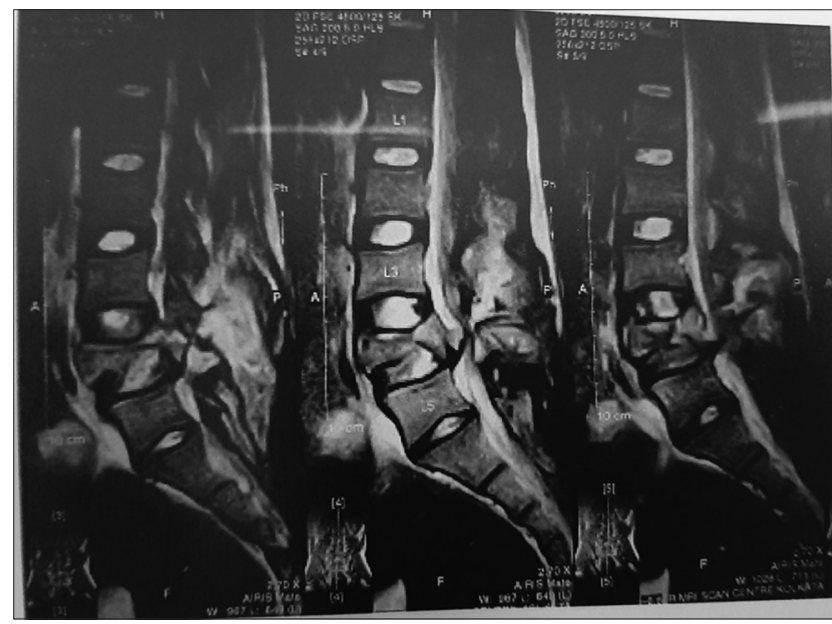

Figure 1: Magnetic resonance imaging showing fracture of $L 4$ with complete cord transaction

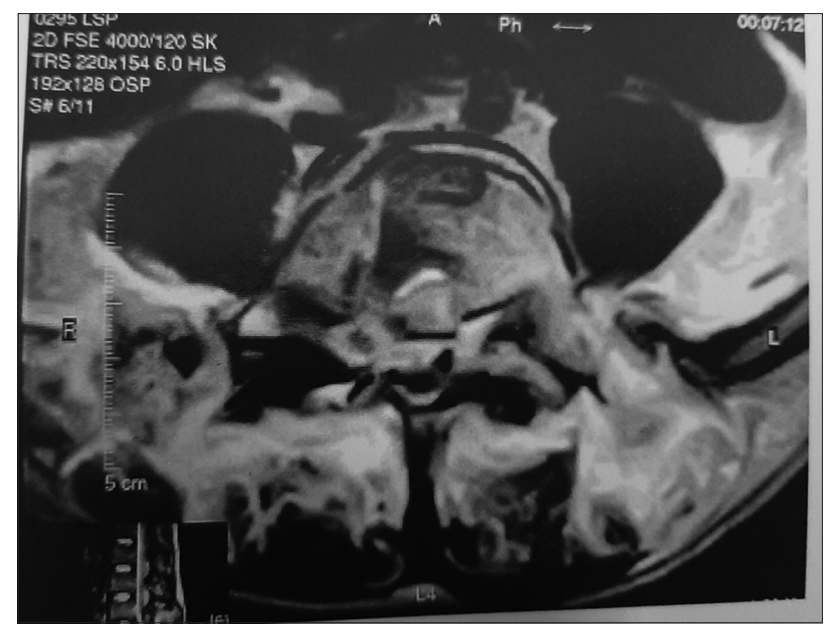

Figure 2: Vertebral body burst fracture
- Fractures involving one or maximally two vertebrae

- Skin condition of the operative field normal patients and party agreed to has a surgical decompression.

\section{Exclusion Criteria}

The following criteria were excluded from the study:

- Patients below 18 years

- Patients unfit for undergoing operation in pre-anesthetic check-up

- Patients with head injury or other gross injuries that may preclude undergoing operation

- $\quad$ Patients with multiple vertebral injuries (> 2 vertebrae)

- Injury of the spinal cord and paraplegia with high dorsal spine (above D8)

- $\quad$ Patients presenting late (more than 1 month after injury)

- Patients with traumatic paraplegia but without signs of cord compression on magnetic resonance imaging (MRI) (where paraplegia is due to cord edema or myelomalacia).

Informed consent was taken after proper counseling and proper pre-anesthetic check-up. The patients were evaluated by X-ray of spine (AP and lateral view) and sometimes computed tomography scan or MRI [Figures 1-3]. Due to financial constraint, contrast myelography was done only few cases. In most cases, pedicle screw with plate or rod was used and posterior stabilization and posterior fusion with corticocancellous bone graft from posterior iliac crest were done. In all the cases, water bed was used during pre-operative and post-operative period to prevent bed sore. Pre-operative and post-operative neurological charts (according to Frankel's grade and American Spinal Cord Injury Association [ASIA] score [motor and sensory]) were maintained with regular assessment for proper post-operative neurological recovery assessment. ${ }^{[9]}$ Recovery from spinal shock was noted using clinical methods like return of bulbocavernosus reflex. Direct or indirect decompression was done. In most of the cases,
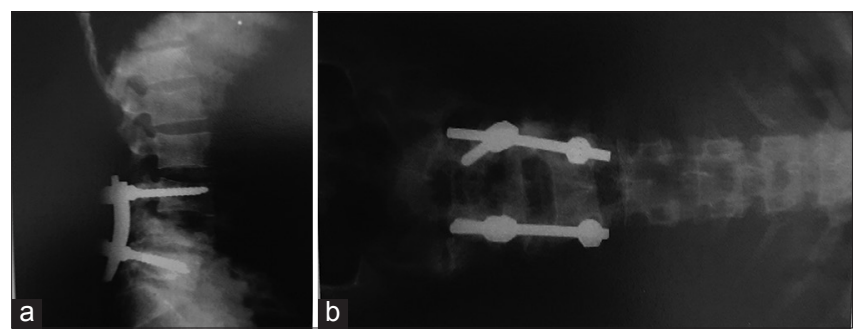

Figure 3: (a) Pedicle screw fixation with rod (lateral view). (b) Pedicle screw fixation with rod (anteroposterior view)

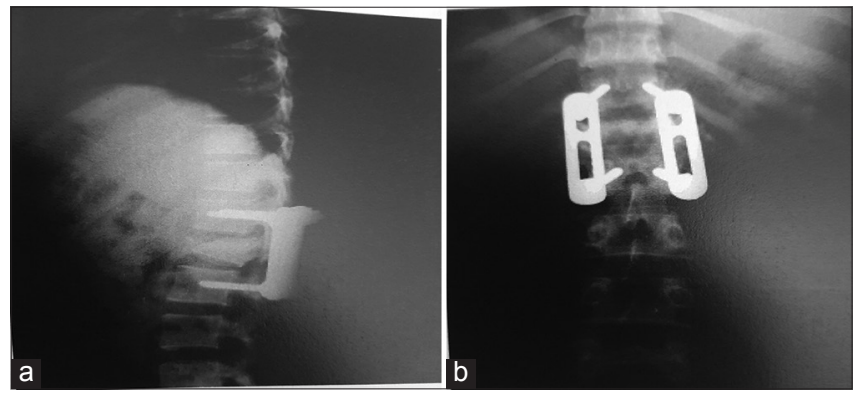

Figure 4: (a) Pedicle screw and plate fixation in lateral view. (b) Pedicle screw and plate fixation in anteroposterior view (same subject) 
laminectomy was done for direct decompression. Decompression was confirmed using a narrow gauge rubber tube. Condition of the spinal cord was checked by direct vision. Any retropulsed fragment compressing on the cord was taken out.

Pedicle screws were inserted into the proximal and distal stable vertebra under image intensification. Then, the fracture was stabilized by rods or plates [Figure $3 a$ and b, Figure $4 a$ and b]. The pedicle entry points were identified (by intersection method and confirmed by image intensifier guidance) and opened, probed all around, and the pedicle screw was introduced. Peroperatively, features such as cord pulsation, cord atrophy, and lacerations were looked for. Postoperatively, wound healing, amount of drainage, neurological recovery, radiological assessment, time taken ambulation, and ultimate recovery were recorded. We used Frankel grade and ASIA scoring system for preand post-operative neurological assessment. ${ }^{[9]}$ In all cases, long dorsolumbar brace was given to the patients after removal of stitches at the $14^{\text {th }}$ post-operative day. Patients were discharged with advice for follow-up.

\section{Follow-up}

First follow-up was done after 2 week, $2^{\text {nd }}$ follow-up after 6 weeks. Then, monthly follow-up until the radiological sign of solid fusion was seen on X-ray. Patients were assessed for neurological recovery and assessment of return of bowel and bladder function in every follow-up. Some case was referred to urosurgery department for the management of bladder function problems.

\section{Results}

Forty-six patients in whom posterior stabilization of the spine was done in this institution and followed up for a period ranging from 6 months to 2 years, 4 of 46 patients lost follow-up. Remaining 42 patients were considered for the study [Table 1]. Majority of traumatic paraplegia was reported to be 21-25 years age group (38.09\%) followed by $26-30$ years age group $(28.57 \%)$. Male was much more common than female cases (76.19\% vs. $23.81 \%)$

Involvement of L3 (19.05\%) was little higher than L1 and L2 (16.66\%) cases. Majority $28(66.66 \%)$ reported at health facility within $0-3$ days of post-injury. ASIA impairment scale was Grade A in 22 (52.38\%) followed by Grade B12 (28.57\%) [Table 2].

Table 1: Demographic characteristics of the traumatic paraplegia subjects $(n=42)$

\begin{tabular}{lc}
\hline Age (Years) & Number $(\%)$ \\
\hline $16-20$ & $8(19.05)$ \\
$21-25$ & $16(38.09)$ \\
$26-30$ & $12(28.57)$ \\
$31-35$ & $4(9.52)$ \\
$36-40$ & $2(4.76)$ \\
Total & 42 \\
Sex incidence $(n=42)$ & \\
Male & Female \\
32 (76.19\%) & $10(23.81)$ \\
Occupation $(n=42)$ & \\
Manual labor & $28(66.67)$ \\
Sedentary worker & $10(23.81)$ \\
Unemployed/housewife & $4(9.52)$ \\
\hline
\end{tabular}

In all cases, some return of power was there, mostly from Grade 3 or Grade 4 or Grade 5 [Table 3].

Return of power in complete paraplegia:

- Hip flexors within Grades 3 and 4.

- Hip abductors/quadriceps/hamstrings: Within Grades 2 and 3.

- Tibialis anterior/EHL/FHL and gastrosoleus: Power did not return at all [Table 4].

In all complete paraplegia cases, autonomic function of bowel and bladder had recovered. In incomplete paraplegia cases, 9 cases became normal and 11 cases still persist hesitancy and incontinence [Table 5].

Table 2: Clinical characteristics of the traumatic paraplegia subjects $(n=42)$

\begin{tabular}{|c|c|c|}
\hline \multicolumn{3}{|c|}{ Vertebra involved } \\
\hline Vertebra & \multicolumn{2}{|c|}{ Number of patients $(n=42)(\%)$} \\
\hline D9 & \multicolumn{2}{|c|}{$1(2.38)$} \\
\hline D10 & \multicolumn{2}{|l|}{$2(4.76)$} \\
\hline D11 & \multicolumn{2}{|l|}{$5(11.90)$} \\
\hline D12 & \multicolumn{2}{|l|}{$6(14.29)$} \\
\hline L1 & \multicolumn{2}{|l|}{$7(16.66)$} \\
\hline L2 & \multicolumn{2}{|l|}{$7(16.66)$} \\
\hline L3 & \multicolumn{2}{|l|}{$8(19.05)$} \\
\hline L4 & \multicolumn{2}{|l|}{$4(9.52)$} \\
\hline L5 & \multicolumn{2}{|l|}{$2(4.76)$} \\
\hline \multicolumn{3}{|c|}{ Days elapsed after injury at presentation } \\
\hline Days & \multicolumn{2}{|l|}{ Number of patients (\%) } \\
\hline $0-3$ & \multicolumn{2}{|l|}{$28(66.67)$} \\
\hline $4-7$ & \multicolumn{2}{|l|}{$10(23.81)$} \\
\hline $8-11$ & \multicolumn{2}{|l|}{$3(7.14)$} \\
\hline $12-15$ & \multicolumn{2}{|l|}{0} \\
\hline $16-19$ & \multicolumn{2}{|l|}{$1(2.38)$} \\
\hline \multicolumn{3}{|c|}{ Time of decompression (post-injury) } \\
\hline Days & Number of patients complete & Incomplete \\
\hline $0-7$ & 9 & 5 \\
\hline $8-14$ & 8 & 11 \\
\hline $15-21$ & 4 & 5 \\
\hline \multicolumn{3}{|c|}{ Mechanism of injury } \\
\hline Road accidents & $18(42.85 \%)$ & \\
\hline Fall from height & $24(57.14 \%)$ & \\
\hline \multicolumn{3}{|l|}{ Paraplegia } \\
\hline Complete & $22(52.38 \%)$ & \\
\hline Incomplete & $20(47.62 \%)$ & \\
\hline \multicolumn{3}{|c|}{ Initial observation (ASIA impairment scale) } \\
\hline Grade & Number & \\
\hline A & $22(52.38 \%)$ & \\
\hline B & $12(28.57 \%)$ & \\
\hline C & $8(19.05 \%)$ & \\
\hline D & Nil & \\
\hline E & Nil & \\
\hline \multicolumn{3}{|c|}{ Classification of fractures } \\
\hline Types & Number of patients & \\
\hline $\begin{array}{l}\text { True wedge } \\
\text { compression }\end{array}$ & $28(66.67 \%)$ & \\
\hline Burst & $10(23.81 \%)$ & \\
\hline $\begin{array}{l}\text { Fracture } \\
\text { dislocation }\end{array}$ & $4(9.52 \%)$ & \\
\hline
\end{tabular}




\section{Stability of Implants}

We got three patients where there was pull-out of the screws completely out of the pedicle. In one patient, there was loosening of the outie/innie followed by loosening of the rod. In all three cases, this happened within 4 weeks postoperatively. In these patients, we had to continue on conservative management and solid bony fusion developed between 12 and 20 weeks [Table 6].

Table 3: Motor recovery in incomplete paraplegia in the study

\begin{tabular}{lccc}
\multicolumn{4}{c}{ subjects $(n=20)$} \\
\hline Muscles & $\begin{array}{c}\text { Power at } \\
\text { presentation }\end{array}$ & $\begin{array}{c}\text { Post-operative } \\
\text { Number of cases }\end{array}$ \\
\hline Hip flexors & 3 & 4 & 5 \\
Hip abductors & 4 & 5 & 1 \\
Quadriceps & 3 & 4 & 3 \\
Hamstrings & 3 & 5 & 2 \\
\multirow{4}{*}{ Tibialis anterior } & 3 & 5 & 2 \\
\multirow{4}{*}{ EHL } & 2 & 4 & 5 \\
& 3 & 4 & 4 \\
FHL & 3 & 5 & 3 \\
\multirow{4}{*}{ Gastrosoleus } & 3 & 5 & 2 \\
& 3 & 4 & 4 \\
& 4 & 4 & 3 \\
& 3 & 5 & 2 \\
& 4 & 4 & 2 \\
& 4 & 5 & 2 \\
\end{tabular}

Table 4: Motor recovery in complete paraplegia in the study subjects

\begin{tabular}{lccc}
\multicolumn{4}{c}{$(n=22)$} \\
Muscles & $\begin{array}{c}\text { Power at } \\
\text { presentation }\end{array}$ & Post-operative & Number of cases \\
\hline Hip flexors & 0 & 3 & 7 \\
Hip abductors & 0 & 2 & 5 \\
Quadriceps & 0 & 2 & 5 \\
& 0 & 3 & 7 \\
Hamstrings & 0 & 2 & 6 \\
Tibialis anterior & 0 & 3 & 6 \\
EHL & 0 & 2 & 8 \\
FHL & 0 & 3 & 4 \\
Gastrosoleus & 0 & 0 & All \\
\hline
\end{tabular}

Table 5: Onset of motor recovery in complete paraplegia $(n=22)$

\begin{tabular}{ll}
\hline Onset of sensory recovery & Number of cases (\%) \\
\hline $1^{\text {st }}$ week & $1(4.54)$ \\
$2^{\text {nd }}$ week & $4(18.18)$ \\
$3^{\text {rd }}$ week & $8(36.36)$ \\
$4^{\text {th }}$ week & $6(27.27)$ \\
$5^{\text {th }}$ week & $3(13.64)$ \\
$6^{\text {th }}$ week & 0 \\
\hline
\end{tabular}

Table 6: Time taken for bony fusion (weeks/months)

\begin{tabular}{lc}
\hline Time (weeks) & Number of patients (\%) \\
\hline 12 weeks & $24(57.14)$ \\
16 weeks & $12(28.57)$ \\
20 weeks & $6(14.29)$ \\
\hline
\end{tabular}

\section{Discussion}

Thoracolumbar junction is the commonest area involved in spinal injury. This area represents the transition from thoracic kyphosis to lumber lordosis and the axis of the body passes in front of this junction when the patient is erect. Hence, there is anterior bending moment working at this junction resulting in maximum stress concentration in this area which may be responsible for implant failure in this junction. ${ }^{[10]}$ Decompression in the spinal injury is one of the most controversial concepts. Both experimental and clinical findings of Benzel et al., Dolan et al., and Maiman et al. clearly documented the role of neural decompression in improving the neurological outcome. ${ }^{[11-13]}$

Regarding neurological recovery, some amount, be it complete or incomplete, be it early, or be it sensory or motor or bowel and bladder function, was noticed in all the cases [Tables 3-5 and 7-9]. As per report published by Denis, there is improved neurological

Table 7: Post-operative sensory recovery (mainly fine touch) ( $n=42)$

\begin{tabular}{ll}
\hline Onset of sensory recovery & Number of cases (\%) \\
\hline $1^{\text {st }}$ week & $22(52.38)$ \\
$2^{\text {nd }}$ week & $12(28.57)$ \\
$3^{\text {rd }}$ week & $6(14.29)$ \\
$4^{\text {th }}$ week & $2(4.76)$ \\
\hline
\end{tabular}

Table 8: Onset of motor recovery in incomplete paraplegia $(n=20)$

\begin{tabular}{lc}
\hline Onset of sensory recovery & Number of cases (\%) \\
\hline $1^{\text {st }}$ week & $10(50)$ \\
$2^{\text {nd }}$ week & $7(35)$ \\
$3^{\text {rd }}$ week & $6(30)$ \\
$4^{\text {th }}$ week & $2(10)$ \\
\hline
\end{tabular}

Table 9: Time taken for recovery of bladder function in incomplete

\begin{tabular}{ll}
\multicolumn{2}{c}{ paraplegia $(n=20)$} \\
\hline Time (weeks) & Number of patients (\%) \\
\hline $2^{\text {nd }}$ & $3(15)$ \\
$3^{\text {rd }}$ & $4(20)$ \\
$4^{\text {th }}$ & $4(20)$ \\
$5^{\text {th }}$ & $4(20)$ \\
$6^{\text {th }}$ & $2(10)$ \\
$8^{\text {th }}$ & $1(5)$ \\
$10^{\text {th }}$ & $1(5)$ \\
$12^{\text {th }}$ & 0 \\
$16^{\text {th }}$ & $1(5)$ \\
\hline
\end{tabular}

Table 10: Comparison among return of muscle power after decompression at different time in incomplete paraplegia

\begin{tabular}{lcccc}
\hline Parameters & Grade 3 & Grade 2 & Grade 1 & Nil \\
\hline $\begin{array}{l}\text { Decompression done within 1 } \\
\text { week (\%) }\end{array}$ & 80 & 20 & - & - \\
$\begin{array}{l}\text { Decompression done within 2 } \\
\text { weeks (\%) }\end{array}$ & 36 & 36 & 18 & 9 \\
$\begin{array}{l}\text { Decompression done within 3 } \\
\text { weeks (\%) }\end{array}$ & 25 & 25 & 25 & 25 \\
\hline
\end{tabular}

Table 11: Comparison among return of muscle power after decompression at different time in complete paraplegia

\begin{tabular}{lcccc}
\hline Parameters & Grade 3 & Grade 2 & Grade 1 & Nil \\
\hline $\begin{array}{l}\text { Decompression done within 1 } \\
\text { week (\%) }\end{array}$ & 11 & 22 & 22 & 45 \\
$\begin{array}{l}\text { Decompression done within 2 } \\
\text { weeks (\%) }\end{array}$ & - & 16 & 16 & 68 \\
$\begin{array}{l}\text { Decompression done within 3 } \\
\text { weeks (\%) }\end{array}$ & - & - & 20 & 80 \\
\hline
\end{tabular}


outcome in effective cord compression after injury, stands for our findings regarding post-operative neurological recovery in spinal injury patients. ${ }^{[14,15]}$

In all the cases of spinal injury, where it was treated by surgical management, the onset of sensory recovery was earlier than motor recovery in all the cases [Tables 10 and 11]. Almost $75 \%$ of the cases showed some amount of sensory recovery within the first 5 days of the operation. The onset of sensory recovery continued for maximally up to $4^{\text {th }}$ week postoperatively in the cases studied by us. According to Kostuik, persistent neural compression can inhibit neurologic recovery and anterior decompression can provide dramatic improvement in many patients. ${ }^{[16]}$ In the present studies, patients were divided into three categories:

- Decompression done within 1 week

- Decompression done in the $2^{\text {nd }}$ week

- Decompression done in the $3^{\text {rd }}$ week.

When decompression done within the $1^{\text {st }}$ week in incomplete paraplegia, $80 \%$ of the patients show Grade 3 power return, whereas $25 \%$ of the patients show return of Grade 3 power when decompression done in the $3^{\text {rd }}$ week in incomplete paraplegia cases [Table 10]. In complete paraplegia cases, $11 \%$ of the patients had return of power up to Grade 3 when decompression done within 1 week, where no cases showed return of Grade 3 power when decompression done after the $2^{\text {nd }}$ or $3^{\text {rd }}$ week [Table 11].

In incomplete paraplegia, $80 \%$ of the patients had onset of sensory recovery within 1 week, when the decompression done within the $1^{\text {st }}$ week [Table 12]. In complete paraplegia, $11 \%$ of the patients had sensory recovery within 2 weeks when decompression done within 1 week [Table 13]. Hence, our conclusion is early decompression definitely has some role regarding motor and sensory function return, both in complete and incomplete paraplegia.

However, the timing of surgery for spinal cord injuries is controversial. Most authors agree that in the presence of a progressive neurological deficit, emergency decompression is indicated. In patients with complete spinal cord injuries or static incomplete spinal cord injuries, some authors advocate delaying surgery for several days to allow resolution of cord edema, whereas others favor early surgical stabilization. There is no conclusive evidence in the literature that early surgical decompression and stabilization improve neurological recovery or that neurological recovery is compromised by a delay of several days.

The role of early surgical stabilization and resultant early mobilization as a method to reduce morbidity and mortality associated with these fractures has sparked significant interest. Surmised benefits of early stabilization include improved

Table 12: Comparison between onsets of sensory recovery after decompression done at different time in incomplete paraplegia

\begin{tabular}{lcccc}
\hline Duration & $1^{\text {st }}$ week (\%) & $2^{\text {nd }}$ week (\%) & $3^{\text {rd }}$ week (\%) & $4^{\text {th }}$ week (\%) \\
\hline $1^{\text {st }}$ week & 80 & 20 & & \\
$2^{\text {nd }}$ week & 27 & 54 & 9 & 9 \\
$3^{\text {rd }}$ week & - & 25 & 50 & 25 \\
\hline
\end{tabular}

Table 13: Comparison between onsets of sensory recovery after decompression done at different time in complete paraplegia

\begin{tabular}{lccccc}
\hline Duration & $1^{\text {st }}$ week & $\begin{array}{c}2^{\text {nd }} \text { week } \\
(\%)\end{array}$ & $\begin{array}{c}3^{\text {rd }} \text { week } \\
(\%)\end{array}$ & $\begin{array}{c}4^{\text {th }} \text { week } \\
(\%)\end{array}$ & $\begin{array}{c}\text { Nil } \\
(\%)\end{array}$ \\
\hline $1^{\text {st }}$ week & - & 11 & 11 & - & 78 \\
$2^{\text {nd }}$ week & - & 12 & - & - & 88 \\
$3^{\text {rd }}$ week & - & - & 20 & 20 & 80 \\
\hline
\end{tabular}

neurological recovery, improved pulmonary function, reduced pain with mobilization, decreased intensive care unit length of stay (LOS), decreased hospital LOS, and decreased mortality. ${ }^{[17,18]}$

Studies by Bohlman et al., Transfeldt et al., Bradford et al., and others have documented return of neurological function after anterior decompression done more than a year after the initial injury. ${ }^{[19-22]}$ For neurological normal patients with unstable spinal injuries and those with non-progressive neurological injuries, we believe that open reduction and internal fixation should be carried out as soon as possible. Mirza et al. in a recent study concluded that patients who sustain acute traumatic injuries to the cervical spine with associated neurologic deficit may benefit from cervical decompression and stabilization within $72 \mathrm{~h}$ of injury. Surgery within $72 \mathrm{~h}$ of injury is not associated with a higher complication rate. Early surgery may improve neurological recovery and decrease hospitalization time in patients with cervical spinal cord injuries. ${ }^{[23]}$ In some patients in our study, it has been found that some return of sensory or motor function was possible even when the MRI findings showed that there was complete transaction of the cord.

About $4 \%$ of these patients initially assessed as complete converted late to incomplete status. Of these sixcases, four regained continence and two became ambulatory with a reciprocal gait. In contrast, those with incomplete paraplegia had the following results: $85 \%$ of the muscles graded $1-2$ on a scale of 5 at 1 month improved to Grade 3 or greater at 1 year and of the muscles graded $0 / 5$ at month fully $55 \%$ regained some volitional control and $26 \%$ regained useful motor function. In most of the patients, the total amount of blood transfused preoperatively and postoperatively to keep the hemoglobin level above $10 \mathrm{~g} \%$ is between 3 and 5 units. In one patient, we had to transfuse 7 units and in three patients 3 units and all these cases late decompression was done.

Regarding the return of bowel and bladder function in all the cases, this was automatic in complete paraplegia. In two cases, where suprapubic cystostomy was done, fistulae developed from bladder to anterior abdominal wall. In one patient, scrotal fistula developed. In 9 out of 20 patients of incomplete paraplegia, bowel and bladder function got almost normal in 6 months follow-up, whereas rest of the patients developed hesitancy or incontinence. However, the bladder sensation returned beck in 15 patients (75\%) of incomplete paraplegia. According to Burns et al., most patients with paraplegia can regain social continence with appropriate rehabilitative training, urologic care, and surveillance. ${ }^{[24]}$ Reinhold et al. reported complete neurologic deficits after injury to the thoracic spine improved in $9 \%$ of the cases, whereas $59 \%$ of the cases with complete neurologic deficit improved after injury to the thoracolumbar junction. ${ }^{[25]}$

Prominence of screw was a problem in only patient in our series which was symptom free. The patients were treated with reassurance and that did not pose any problem to the patient in 1 year follow-up. Post-operative neurologic deficit can be classified according to the severity of the deficit. Minor deficit takes the form of radiculopathy, sensory impairment without motor loss, temporary dysesthesias in the feet, or lesser degrees of neurologic deficit. Major deficits are considered those in which the patient suffers from postoperative paraparesis, paraplegia, or a spinal cord syndrome. Among these $70 \%$ deficits are transient, according to the literature. The Stagnara wake up test is still the gold standard test to detect gross motor deficit. In our series, we had one patient with incomplete paraplegia who had deterioration of 1 grade of power postoperatively. ${ }^{[2]}$ The patient was taken back to operation 
Table 14: Amount of blood loss (as calculated by number of mops soaked and blood in sucker machine) $(n=42)$

\begin{tabular}{lc}
\hline Units of blood & Number of patients (\%) \\
\hline $1.5 \mathrm{lit}$ & $8(19.05)$ \\
$1.2 \mathrm{lit}$ & $8(19.05)$ \\
$900 \mathrm{ml}$ & $21(50)$ \\
$600 \mathrm{ml}$ & $5(11.9)$ \\
\hline
\end{tabular}

theater immediately for exploration to find out the pathology for deterioration of power. A block of bone, given as a bone graft, found to be compressing on the cord and it was taken out. The recovery was uneventful.

Some surgeons advocate surgical treatment with a view of restoring the spinal canal and stabilizing the spine ${ }_{r}^{[27,28]}$ while others recommend non-operative treatment. ${ }^{[29,30]}$ Some reports suggest that although surgical removal of bony fragments may restore the spinal canal, it does not improve the chance of neurological recovery. ${ }^{[31-33]}$ In Sahoo et al. study, 53.33\% of patients operated more than 2 weeks of injury showed improvement as compared to $33 \%$ operated within 2 weeks of injury which was not statistically significant $(P=0.231) \cdot{ }^{[34]}$ Bohlman and Freehafer have reported that greater neurologic recovery occurs if surgical decompression is performed within 2 years after the injury. ${ }^{[35]}$

In the present study, 21 (50\%) cases average blood loss was $900 \mathrm{ml}$. Almost 16 (38.09\%) cases average blood loss was more than $900 \mathrm{ml}$ [Table 14]. Suman et al. study revealed that average blood loss was between 500 and $700 \mathrm{ml} .{ }^{[7]}$ In the study by Cotler et al., of the 44 patients, 14 patients improved neurologically, that is, $31.9 \% .{ }^{[36]}$ Aebi et al. ${ }^{[10]}$ showed $64.4 \%$ neurological improvement. Nasser et al. reported that neurological improvement occurred in 50\% of cases. The neurological improvement achieved was fair and comparable to other studies. Non-operative treatment is indicated for stable injuries without the potential for progressive deformity or neurological injury. The most devastating complication of nonoperative treatment is development of neurological deterioration. Denis $^{[15]}$ noted that 6 of 29 nonoperatively treated burst fractures developed neurological deficit. On the other hand, Reid et al. ${ }^{[37]}$ and Canter et al. ${ }^{[38]}$ noted no neurological worsening in their nonoperatively treated patients with burst fractures.

\section{ConcLusion}

The decision of operative management should be case based. Injuries to spine are dreaded problems. They cause infinite morbidity and disability to the patient. If not treated urgently and rationally, patient may be confined to bed for his life. Hence, our conclusion is that early decompression definitely has some role regarding motor and sensory function return, both in complete and incomplete paraplegia.

\section{References}

1. Mikles MR, Stchur RP, Graziano GP. Posterior instrumentation for thoracolumbar fractures. J Am Acad Orthop Surg 2004;12:424-35.

2. Kirkpatrick AW, McKevitt E. Thoracolumbar spinal fractures, is there a problem? Can J Surg 2002;45:21-4.

3. Henderson RL, Reid DC, Saboe LA. Multiple noncontiguous spine fractures. Spine 1991;16:128-31.

4. Prabhakar MM, Rao BS, Patel L. Thoracolumbar burst fracture with complete paraplegia: Rationale for second-stage anterior decompression and fusion regarding functional outcome. J Orthop Traumatol 2009;10:83-90.
5. Bucholz WR, Heckman DJ. Rockwood and Greens Fractures in Adults. $5^{\text {th }}$ ed., Vol. 2. United States: Lippincott Williams \& Wilkins; 2001. p. 1293-1466.

6. Guttman L. Spinal Cord Injuries-comprehensive Management and Research. Oxford: Blackwell Scientific Publications; 1976. p. 137-76.

7. Suman NV, Chincholi S. Management and outcome of thoracolumbar spine injury cases at a tertiary care hospital. Int J Orthop Sci 2017;3:145-8.

8. Scivoletto G, Morganti B, Molinari M. Early versus delayed inpatient spinal cord injury rehabilitation: An Italian study. Arch Phys Med Rehabil 2005;86:512-6.

9. Maynard FM Jr., Bracken MB, Creasey G, Ditunno JF Jr., Donovan WH, Ducker $\mathrm{TB}$, et al. International standards for neurological and functional classification of spinal cord injury. American spinal injury association. Spinal Cord 1997;35:266-74.

10. Aebi M, Etter C, Kehl T, Thalgott J. Stabilization of the lower thoracic and lumbar spine with internal spinal fixation system: Indications, techniques, and the first results of treatment. Spine (Phila Pa 1976) 1987;12:544-51.

11. Benzel EC. Short segment compression instrumentation for selected thoracic and lumbar spine fractures: The short-rod/two claw technique. J Neurosurg 1993;79:335-40.

12. Dolan EJ, Tator CH, Endrenyi L. The value of decompression for acute experimental spinal cord compression injury. J Neurosurg 1980;53:749-55.

13. Maiman DJ, Larson SJ, Benzel EC. Neurological improvement associated with late decompression of the thoracolumbar spinal cord. Neurosurgery 1984;14:302-7.

14. Denis F. Spinal instability as defined by the three-column spine concept in acute spinal trauma. Clin Orthop Relat Res 1984;189:65-76.

15. Denis F, Armstrong GW, Searls K, Matta L. Acute thoracolumbar burst fractures in the absence of neurological deficit (a comparison between operative and nonoperative treatment). Clin Orthop Relat Res 1984;189:142-9.

16. Kostuik JP. Anterior spinal cord decompression for lesions of the thoracic and lumbar spine, techniques, new methods of internal fixation results. Spine 1983;8:512-31.

17. Bellabarba C, Fisher C, Chapman JR, Dettori JR, Norvell DC. Does early fracture fixation of thoracolumbar spine fractures decrease morbidity or mortality? Spine (Phila Pa 1976) 2010;35 Suppl 9:S138-45.

18. AbdelFatah MA. The walking recovery one year after surgical management of thoracolumbar burst fracture in paraplegic patients. Neurol Med Chir (Tokyo) 2017;57:467-71.

19. Bradford DS, McBride GG. Surgical management of thoracolumbar spine fractures with incomplete neurologic deficits. Clin Orthop Relat Res 1987;218:201-16.

20. Bradford DS, Akbarnia BA, Winter RB, Seljeskog EL. Surgical stabilization of fracture and fracture dislocations of the thoracic spine. Spine 1977;2:185-96.

21. Bohlman HH, Bahniuk E, Raskulinecz G, Field G. Mechanical factors affecting recovery from incomplete cervical spinal cord injury: A preliminary report. Johns Hopkins Med J 1979;145:115-25.

22. Transfeldt EE, White D, Bradford DS, Roche B. Delayed anterior decompression in patients with spinal cord and cauda equina injuries of the thoracolumbar spine. Spine 1990;15:953-57.

23. Mirza SK, Krengel WF, Chapman JR, Anderson PA, Bailey JC, Grady MS, et al. Early versus delayed surgery for acute cervical spinal cord injury. Clin Orthop Relat Res 1999;359:104-14.

24. Burns AS, O'Connell C. The challenge of spinal cord injury care in the developing world. J Spinal Cord Med 2012;35:3-8.

25. Reinhold M, Knop C, Beisse R, Audigé L, Kandziora F, Pizanis A, et al. Operative treatment of traumatic fractures of the thoracic and lumbar spinal column. Part III: Follow-up data. Unfallchirurg 2009;112:294-316.

26. Vauzelle C, Stagnara P, Jouvinroux P. Functional monitoring of spinal cord activity during spinal surgery. Clin Orthop Relat Res 1973;93:173-8. 
27. Hashimoto T, Kaneda K, Abumi K. Relationship between traumatic spinal canal stenosis and neurologic deficits in thoracolumbar burst fractures. Spine 1988;13:1268-72.

28. Mumford J, Weinstein JN, Spratt KF, Goel VK. Thoracolumbar burst fractures: The clinical efficacy and outcome of non-operative management. Spine 1993;18:955-70.

29. Knight RQ, Stomelli DP, Chan DP. Comparison of operative versus non-operative treatment of lumbar burst fractures. Clin Orthop 1993;293:112-21.

30. Mohanty SP, Hammidreza K, Shahrokh E. A comparative analysis of operative and non-operative management of thoracic and lumbar spine injuries. Indian J Orthop 1999;33:267-70.

31. El Masry WS, Short DJ. Current concepts: Spinal injuries and rehabilitation. Curr Opin Neurol 1997;10:484-92.

32. Lemons V, Wagner F, Montesano P. Management of thoracolumbar fractures with accompanying neurological injury. Neurosurgery
1992;30:667-71.

33. Shuman WP, Rogers JV, Sickler ME, Hanson JA, Crutcher JP, King HA, et al. Thoracolumbar burst fractures: $C T$ dimensions of the spinal canal relative to postsurgical improvement. AJR Am J Roentgenol 1985; 145:337-41.

34. Sahoo SS, Gupta D, Mahapatra AK. Traumatic paraplegia: Outcome study at an apex trauma centre. Indian J Neurotrauma 2011;8:33-6.

35. Bohlman $\mathrm{HH}$, Freehafer $\mathrm{A}$. Late anterior decompression of spinal cord injuries. J Bone Joint Surg Am 1975;57:10-25.

36. Cotler JM, Spivak JM, Vaccaro AR. Thoracolumbar spine trauma: II. Principles of management. J Am Acad Orthop Surg 1995;3:353-60.

37. Reid DC, Hu R, Davis LA, Saboe LA. The nonsurgical treatment burst fractures of the thoracolumbar junction. J Trauma 1988;28:1188-94.

38. Canter JB, Lebwohl NH, Garvey T, Eismont FJ. Nonoperative management of stable thoracolumbar burst fractures with early ambulation and bracing. Spine 1993;181:971-6. 